\title{
Patent foramen ovale: to close or not to close - still the question
}

Drożny otwór owalny: zamykać czy nie zamykać - pytanie wciąż otwarte

\author{
Magdalena Kumor \\ Department of Congenital Heart Disease, Institute of Cardiology, Warsaw, Poland
}

Post Kardiol Interw 2012; 8, 1 (27): 42-47 DOI: $10.5114 /$ pwki.2012.27924

Key words: patent foramen ovale, cryptogenic stroke, migraine, decompression illness

Słowa kluczowe: drożny otwór owalny, udar kryptogenny, migrena, choroba dekompresyjna

\section{Introduction}

Patent foramen ovale (PFO) is a physiological remnant of the foramen ovale, a connection between atria which is essential in fetal circulation. It is assumed to be a normal variant, as it is present in $20-27 \%$ of the population in autopsy studies but only in $10-15 \%$ of patients in contrast transesophageal echocardiography (TEE) [1]. This discrepancy may be due to increase in size of PFO with age.

Patent foramen ovale is a flap-like tunnel between atrial septa: primum and secundum in the location of the fossa ovalis. It is potential communication for right-to-left shunt. Patent foramen ovale usually opens during Valsalva manoeuvre and other physiological situations when pressure in the right atrium exceeds the left atrium, that is when negative pressure in the chest (e.g. during deep breath, cough, sneezing) raises systemic venous return. Patent foramen ovale remains unrecognized and silent in most cases.

The Mayo Clinic autopsy study showed that the size of a PFO increases from a mean of $3.4 \mathrm{~mm}$ in the first decade to $5.8 \mathrm{~mm}$ in the $10^{\text {th }}$ decade of life, as the valve of the fossa ovalis stretches with age [1]. The prevalence of PFO presence decreasing with age may be due to shorter life of patients with PFO or spontaneous closure. Recent evidence from surgical data show the opposite, that PFO prevalence is not related to age [2].

Patent foramen ovale (PFO) is associated with cryptogenic strokes, recurrent transient neurological deficits, sleep apnoea, decompression illness, and migraines [3].

\section{Patent foramen ovale and cryptogenic stroke}

Cryptogenic stroke represents up to $40 \%$ of all ischaemic strokes [4]. It is a diagnosis by exclusion, based on thorough investigation of other established causes of stroke.

The first paradoxical embolism related to PFO was described by Cohnheim in 1877 . The most likely mechanism of cryptogenic stroke is paradoxical embolization through the PFO, but other possible hypotheses, such as the formation and release of thrombus from within the PFO tunnel and the passage of vasoactive humoral substances that are normally degraded in the pulmonary circulation, have also been suggested [5].

It is hard to show clearly, according to evidence-based medicine, that the PFO is worth closing, because there are no randomized positive studies showing a benefit of the closing strategy over pharmacological treatment. The cause may be relatively short follow-up of one randomized study. On the other hand, the device closing procedure after cryptogenic stroke has become popular and is used widely with enthusiasm by physicians. It is hard to deny the procedure to an individual patient, as data from observational studies are so promising.

The first studies associating PFO with cryptogenic stroke were published in the 1980s [6, 7]. In 1992, in a study on 146 patients after stroke, researchers found significantly higher prevalence of PFO in patients with cryptogenic stroke compared to patients with known cause of stroke, both in younger (less than 55 years) and in older patients [8]. 
A study with diffusion-weighted magnetic resonance imaging brain scanning in patients $(n=60)$ with non-major acute pulmonary embolism showed that up to $33 \%(n=5 / 15)$ of the patients with a PFO had silent brain infarcts at admission. This is significantly more common than in patients without a PFO, which was reported at $2 \%$ ( $n=1 / 45, p=0.003$ ) [9]. Numerous retrospective, casecontrol studies have also shown a higher prevalence of PFO in patients with cryptogenic stroke. The authors of a meta-analysis of these studies reported only a significant association of PFO and atrial septal aneurysm in patients younger than 55 years [10].

On the other hand, there are studies in patients older than 55 years $(n=372)$, where PFO was significantly more common in cryptogenic stroke patients $(28.3 \%)$ than in patients with a known cause of stroke $(11.9 \%, p<0.001)$ [11]. Similarly, another study, in 132 consecutive patients years after stroke older than 55 years, showed higher prevalence of PFO and atrial septal aneurysm in a subgroup with cryptogenic stroke in comparison with patients with known cause of stroke. It was also true in patients older than 75 years of age [12].

Alsheikh-Ali et al. applied the Bayes theorem to the available data, to ascertain the probability of PFO being incidental in a patient with cryptogenic stroke. They came to the conclusion that PFO may represent an incidental finding in 33-48\% of cryptogenic strokes when in isolation, but only in $11 \%$ when associated with bulging of the interatrial wall (so-called atrial septal aneurism - ASA). These figures drop to $20 \%$ and $9 \%$, respectively, in patients less than 55 years old [13]. Recently there were several studies published calling into question the link between PFO and stroke.

A cause-effect relationship between PFO and cryptogenic stroke has not been convincingly demonstrated. In particular, the extent of the PFO-related stroke risk in the general population still remains controversial [14]. Furthermore, several studies have consistently found that the presence of a PFO does not inherently increase the risk of recurrent stroke [4, 15-19]. This may be due to the relatively low overall rate of stroke recurrence in patients with cryptogenic stroke and PFO, ranging in studies from 0 to $12 \%$ per year, with an average annualized risk across studies of approximately $2 \%[17,18]$. The higher rate of recurrence in a multicenter, prospective study was observed in patients with both atrial septal aneurysm and PFO (15\%) compared with PFO alone (2.3\%) and no atrial septal pathology (4.3\%) or atrial septal aneurysm alone (0\%), all treated with $300 \mathrm{mg}$ aspirin [17]. The data that patients with PFO alone, whether small or large, while on aspirin do not have a higher recurrent rate of stroke than patients without septal abnormalities is consistent with previous small retrospective studies of the authors [16, 20-23]. There are data showing that the risk for recurrent thromboembolic events in patients with both atrial septal aneurysm and PFO was not significantly increased compared with patients with only PFO (RR 1.0, 95\% Cl 0.2-4.7, $p=0.95$ ) [24].

Also, two large prospective studies, recently published, showed a very low rate of first cerebrovascular events in asymptomatic subjects with PFO [25, 26]. Among 486 patients of the CODICIA trial PFO, with substantial rightto-left shunting presence or concomitant atrial septal aneurysm, was not an independent risk factor of recurrent stroke either in young patients or in the whole study group [27]. The surgical closure of incidental PFO during open heart surgery may actually increase postoperative risk of stroke [28].

Finally, one non-randomized prospective study on 446 patients, mean follow-up of more than 4 years, showed a low cerebrovascular recurrent events rate in patients with PFO independently of treatment - closure versus medical therapy. The event rate was similar to that observed in the general population [29]. Both treatment strategies were effective. Clinical conditions potentially associated with cerebral or peripheral embolism, such as mitral valve disease, atrial fibrillation and aortic atherosclerosis, were relatively common in this group. Also, few patients, in whom thrombotic status was assessed (assessed in 165 patients), had prothrombotic abnormalities [29]. Surprisingly, KaplanMeier analysis revealed survival free from cerebrovascular events during follow-up: patients without PFO closure showed a statistically significant better prognosis, in comparison to those who underwent PFO closure [29]. The weakness of the studies is relatively short follow-up - up to 5 years. Recently, a study with a mean follow-up period of 15 years was published, in 86 patients, less than 75 years old at the time of enrolment. The recurrent risk of stroke was rather high $-15 \%$ after a mean period of 4.9 years, reflecting a calculated event rate of $0.98 \%$ per year in this cohort [30]. The occurrence of stroke was not associated with differences in baseline data, the presence of atrial septal aneurysm, PFO size or chosen treatment (PFO closure, anticoagulation, antithrombotic therapy). It should be noted that most patients in this study were treated medically (only 3 had intervention therapy). Also, groups were relatively small. It seems important that patients with subsequent stroke have statistically significantly more multiple risk factors [30]. In another study of 280 patients with mean follow-up of 2.6 years, the recurrence rate was $0.6 \%$ per year for patients treated with interventional closure devices and $13 \%$ per year for medical treatment with acetylsalicylic acid [31]. The latest study analyses have shown, despite doubts about PFO, that there are in the literature more studies with patients treated with device closure than medically: 7013 patients vs. 1093.

A meta-analysis of observational, non-randomized trials gave conflicting results for one randomized CLOSURE I trial $[32,33]$. In the observational studies the incidence rate of recurrent stroke was 0.36 (95\% Cl 0.24-0.56) events per 100 person-years with closure versus 2.53 (95\% Cl 1.91-3.35) 
events per 100 person-years with medical therapy. The incidence rate for the closure arm in the CLOSURE I trial was higher by almost 4 times $(1.34,95 \% \mathrm{Cl} 0.69-2.34)$ and did not differ from medical treatment. The observational studies are in favour of closing PFO in secondary prevention, but CLOSURE I failed to show superiority of the closing strategy. There are many possible reasons why CLOSURE I failed. First, the lower event rate than previously reported in the medical arm suggests that baseline risk in the trial population was lower. Second, the higher rates in the closure arm may reflect unrealistic estimates in observational studies. Authors are less keen to publish unfavourable results. Third, the researchers failed to select high-risk patients with PFO-related events in the CLOSURE trial. High-risk patients with clinical indicators of paradoxical embolism, such as large shunt, associated atrial septal aneurysm, Valsalva manoeuvre at onset of stroke, evidence of deep vein thrombosis, evidence of a hypercoagulable state, stroke recurrence despite antithrombotic treatment, multiple clinical cerebrovascular events or multiple ischaemic lesions at brain magnetic resonance imaging (MRI) and absence of any conventional stroke risk factor were probably more often treated with closure off-protocol, not included in the trial $[13,34,35]$. Moreover, the 2-year follow-up may be inadequate to fully capture the benefit of the intervention.

Importantly, the number of patients included in observational studies is 10 times larger than the number of patients enrolled in the CLOSURE I trial. In summary, the results of the CLOSURE I challenge the credibility of observational evidence strongly favouring mechanical closure over medical therapy [32].

Although PFO is often closed as secondary prevention in cryptogenic stroke, the benefit of this treatment remains unclear. The RoPE study concerns developing a risk model for application to ongoing randomized trials of percutaneous PFO closure for cryptogenic stroke. The aim of this study is to identify patients who are most likely to benefit from preventive treatments for PFO-related stroke recurrence, such as PFO closure. The study is to test other factors that may influence probability that PFO is the cause, such as patients' clinical, radiographic and echocardiographic characteristics [36]. It was postulated earlier that to show the benefit of PFO closure, the PFO must be the cause of stroke, not an incidental finding [13, 34, 36]. Other factors such as occult atrial fibrillation, sub-threshold aortic atheroembolic disease, and coagulation disorders must be excluded. Silent atrial fibrillation is not easy to detect. Patients with cryptogenic stroke should be screened with electrocardiogram (ECG)monitoring for a longer time, as the detection of arrhythmia is difficult. Recently, brief intermittent long-term ECG recordings at regular time intervals were more effective than short-term continuous ECG in atrial fibrillation diagnosis [37]. Also, subclinical atrial tachyarrhythmias, without clinical atrial fibrillation, significantly increase the risk of ischaemic stroke or systemic embolism [38]. Presence of multiple risk factors (hypertension, diabetes, smoking, obesity, heart failure) may contribute to lower propensity of PFO to be the cause of stroke. Hopefully, the ongoing randomized trials REDUCE (with Hexel septal occluder), PC-Trial (with Amplatzer PFO occluder), RESPECT (with Amplatzer PFO occluder) and CLOSE (with any device) will provide a final answer whether closing is the right strategy [39].

We must keep in mind that invasive procedures are associated with periprocedural risk. There were rarely described serious complications with PFO closure such as tamponade, embolization with device or milder transient supraventricular arrhythmia or atrial fibrillation [32, 40, 41]. Also in observational studies the periprocedural risk was reported as low [42]. In the MIST randomized trial periprocedural complications were reported in up to $11 \%$ of patients.

The frequency and causes of surgical explantation of PFO closure devices were evaluated in a multicentre survey. More than 13000 closures were performed in 9 years. Only 38 devices ( $0.28 \%$ [ $95 \%$ confidence interval: $0.20 \%$ to $0.37 \%]$ ) required surgical removal. There was a wide range of causes cited for these removals. The most common reason for explantation was chest pain $(n=14)$, often determined to be secondary to nickel allergy to the PFO device. Other reasons for explantation included persistence of a residual shunt $(n=12)$, the presence of thrombus on the device $(n=4)$, pericardial effusion $(n=2)$, perforation of the atrium or aortic root $(n=2)$, recurrent strokes $(n=1)$, the development of endocarditis $(n=1)$, and undocumented reasons $(n=2)$. The frequency of removal seems to be device-dependent: in this survey the rate of explantation was 1 in 126 for CardioSEAL devices, 1 in 480 for Amplatzer devices, and 1 in 600 for the Helex device [43].

The closing strategy leads to increased risk of infective endocarditis 6 months after the procedure and potentially increased risk of bleeding during aspirin or double antiplatelet or warfarin therapy at least 3 months after the procedure.

According to the American Heart Association and American Stroke Association, for patients with an ischaemic stroke or TIA and a PFO, antiplatelet therapy is reasonable (class Ila; level of evidence B) and there are insufficient data to make a recommendation regarding PFO closure in patients with stroke and PFO (class IIb; level of evidence C) $[44,45]$. Also physicians should be encouraged to enrol patients in clinical randomized studies.

\section{Migraine}

Migraine is a new potential indication for PFO closure. Patent foramen ovale and migraine were suspected to be linked when improvement in the frequency and severity of symptoms was observed after PFO closure for other reasons [46]. As in cryptogenic stroke, there is still no hard evidence for the PFO closing strategy in migraine. There are several reasons why it is difficult to show the efficacy 
of new treatment. Migraine is known for its spontaneous variability and for a placebo response rate of around 20$30 \%$ in well-conducted contemporary clinical trials. The response rate to preventive medications is about $50 \%$. Most observations that closing PFO cures migraine were in patients after stroke, an event which may alter the course of migraine per se. Also medication used in some studies after PFO closure, that is aspirin [47, 48] and clopidogrel, show a small effect on migraine. Nonetheless, migraine symptoms were reduced in $75 \%$ of patients after PFO closure for different reasons [49]. The positive effect was observed regardless of residual shunt and was more pronounced in migraineurs with aura [49-52].

Decrease in migraine frequency after stroke and before PFO closure was found in a small group of patients [53]. The authors hypothesize that the results found after device implantation were confounded by the natural history of migraine. But they also observed further decline after closure. They speculated that it could be also due to aspirin after stroke [53].

Unfortunately, the randomized trial MIST failed to show a significant difference between medical and closure strategies. The problem needs more studies because of methodological problems reported in this trial [54]. There are two remaining trials actively randomizing patients: Percutaneous closure of PFO in Migraine with Aura (PRIMA), and Prospective Randomised investigation to Evaluate incidence of headache reduction in subjects with Migraine and PFO using the Amplatzer PFO Occluder compared to Medical management (PREMIUM). Hopefully they will provide an answer.

\section{Decompression illness}

Patent foramen ovale was 2 to 6 times more frequent in a population of divers with decompression illness than in the general population [55]. However, as yet it is not assumed to be the cause of decompression illness. Many divers suffer from decompression disease without PFO being present. Many with PFO were symptomless. Even if decompression illness is associated with PFO, the risk is low because decompression illness is rare. In most cases symptoms are mild and entirely reversible with treatment. The Diver Alert Network says diving does not cause stroke, but it does expose individuals to elevated partial pressures and elevated hydrostatic pressure. A 2001 study reported in the Journal of Occupational Health concluded that a group of Japanese divers who held their breath during a technique called free diving appeared to be at increased risk for cerebral injuries with symptoms similar to those common in stroke victims. The researchers discovered that 13 of 16 divers in the study had histories of stroke-like neurological symptoms. None of the divers had vascular disease or risk factors for stroke. The symptoms occurred during or after repetitive deep dives [56]. Decompression illness in recreational divers is extremely rare, occurring after only $0.005 \%$ to $0.08 \%$ of dives, according to Divers Alert Network Annual Diving Report 2007 - 4 cases of decompression sickness (DCS) in 14,000 dives. Because it is so rare, screening for PFO in recreational divers is not recommended. A safe strategy would be to reduce the venous bubble load, because bubbles are the cause of decompression illness. This can be accomplished by avoiding dives that require decompression stops, by limiting bottom time, or by appropriate use of oxygen-enriched breathing mixes [57]. On the other hand, assessment of PFO is often recommended for divers with severe or recurrent neurological decompression sickness, especially when they occur with a safe diving protocol. Some divers who wish to return to unrestricted diving choose to have the PFO closed, but a careful discussion of risks and benefits is needed before this procedure can be recommended [57, 58]. Every patient should be treated individually, with detailed risk assessment.

\section{Conclusions}

There is a possibility that some patients with cryptogenic stroke, some with migraine with aura and some with decompression sickness might benefit from closure of PFO, but there is little evidence that a routine closure strategy is appropriate. Even more careful indication assignment to the closing strategy in patients with cryptogenic stroke is essential, especially exclusion of other possible causes of stroke such as subclinical atrial fibrillation. The randomized trials, when completed, may provide the answer "to close or not to close".

\section{References}

1. Hagen PT, Scholz DG, Edwards WD. Incidence and size of patent foramen ovale during the first 10 decades of life: an autopsy study of 965 normal hearts. Mayo Clin Proc 1984; 59: 17-20.

2. Hart S, Krasuski R. Incidence of asymptotic patent foramen ovale according to age. Ann Intern Med 2009; 150: 431-432.

3. Johansson MC, Eriksson P, Dellborg M. The significance of patent foramen ovale: a current review of associated conditions and treatment. Int J Cardiol 2009; 134: 17-24.

4. Sacco RL, Ellenberg JH, Mohr JP, et al. Infarcts of undetermined cause: the NINCDS Stroke Data Bank. Ann Neurol 1989; 25: 382-390.

5. Halperin JL, Fuster V. Patent foramen ovale and recurrent stroke: another paradoxical twist. Circulation 2002; 105: 2580-2582.

6. Lechat P, Mas JL, Lascault G, et al. Prevalence of patent foramen ovale in patients with stroke. N Engl J Med 1988; 318: 1148-1152.

7. Webster MW, Chancellor AM, Smith HJ, et al. Patent foramen ovale in young stroke patients. Lancet 1988; 2: 11-12.

8. Di Tullio M, Sacco RL, Gopal A, et al. Patent foramen ovale as a risk factor for cryptogenic stroke. Ann Intern Med 1992; 117: 461-465.

9. Clergeau MR, Hamon M, Morello R, et al. Silent cerebral infarcts in patients with pulmonary embolism and a patent foramen ovale. A prospective diffusion-weighted MRI study. Stroke 2009; 40: 3758-3762.

10. Overell JR, Bone I, Lees KR. Interatrial septal abnormalities and stroke: a meta-analysis of case-control studies. Neurology 2000; 55: 1172-1179. 
11. Handke M, Harloff A, Olschewski M, et al. Patent foramen ovale and cryptogenic stroke in older patients. N Engl J Med 2007; 357: 2262-2268.

12. Force M, Massabuau P, Larrue V. Prevalence of atrial septal abnormalities in older patients with cryptogenic ischemic stroke or transient ischemic attack. Clin Neurol Neurosurg 2008; 110: 779-783.

13. Alsheikh-Ali AA, Thaler DE, Kent DM. Patent foramen ovale in cryptogenic stroke: incidental or pathogenic? Stroke 2009; 40: 2349-2355.

14. Messè SR, Kasner SE. Is closure recommended for patent foramen ovale and cryptogenic stroke? Patent foramen ovale in cryptogenic stroke: not to close. Circulation 2008; 118: 1999-2004.

15. De Castro S, Cartoni D, Fiorelli MMR, et al. Morphological and functional characteristics of patent foramen ovale and their embolic implications. Stroke 2000; 31: 2407-2413.

16. Bogousslavsky J, Garazi S, Jeanrenaud X, et al. Stroke recurrence in patients with patent foramen ovale: the Lausanne Study. Lausanne Stroke with Paradoxal Embolism Study Group. Neurology 1996; 46: 1301-1305.

17. Mas JL, Arquizan C, Lamy C, et al.; Patent Foramen Ovale and Atrial Septal Aneurysm Study Group. Recurrent cerebrovascular events associated with patent foramen ovale, atrial septal aneurysm, or both. N Engl J Med 2001; 345: 1740-1746.

18. Almekhlafi MA, Wilton SB, Rabi DM, et al. Recurrent cerebral ischemia in medically treated patent foramen ovale: a metaanalysis. Neurology 2009; 73: 89-97.

19. Messe SR, Silverman IE, Kizer JR, et al. Practice parameter: recurrent stroke with patent foramen ovale and atrial septal aneurysm: report of the Quality Standards Subcommittee of the American Academy of Neurology. Neurology 2004; 62: 1042-1050.

20. Cujec B, Mainra R, Johnson DH. Prevention of recurrent cerebral ischemic events in patients with patent foramen ovale and cryptogenic strokes or transient ischemic attacks. Can J Cardiol 1999; 15: 57-64 (Abstract).

21. Hausmann D, Mügge A, Daniel WG. Identification of patent foramen ovale permitting paradoxic embolism. J Am Coll Cardiol 1995; 26: 1030-1038 (Abstract).

22. De Castro S, Cartoni D, Fiorelli M, et al. Morphological and functional characteristics of patent foramen ovale and their embolic implication. Stroke 2000; 31: 2407-2413.

23. Hanna JP, Sun JP, Furlan AJ, et al. Patent foramen ovale and brain infarct. Echocardiographic predictors, recurrence, and prevention. Stroke 1994; 25: 782-786.

24. Windecker S, Wahl A, Chatterjee T, et al. Percutaneous closure of patent foramen ovale in patients with paradoxical embolism: longterm risk of recurrent thromboembolic events. Circulation 2000; 101: 893-898

25. Di Tullio MR, Sacco RL, Sciacca RR, et al. Patent foramen ovale and the risk of ischemic stroke in a multiethnic population. J Am Coll Cardiol 2007; 49: 797-802.

26. Meissner I, Khandheria BK, Heit JA, et al. Patent foramen ovale: innocent or guilty? Evidence from a prospective population-based study. J Am Coll Cardiol 2006; 47: 440-445.

27. Serena J, Marti-Fábregas J, Santamarina E, et al; CODICIA, Rightto-Left Shunt in Cryptogenic Stroke Study; Stroke Project of the Cerebrovascular Diseases Study Group, Spanish Society of Neurology. Recurrent stroke and massive right-to-left shunt: results from the prospective Spanish multicenter (CODICIA) study. Stroke 2008; 39: 3131-3136.
28. Krasuski RA, Hart SA, Allen D, et al. Prevalence and repair of intraoperatively diagnosed patent foramen ovale and association with perioperative outcomes and long-term survival. JAMA 2009; 302: 290-297.

29. Faggiano P, Frattini S, Piovesana P, et al. Low cerebrovascular event rate in subjects with patent foramen ovale and different clinical presentations. Results from a prospective non randomized study on a population including patients with and without patent foramen ovale closure. Int J Cardiol 2010; 156: 47-52.

30. Fischer D, Gardiwal A, Haentjes J, et al. Susteined risk of recurrent thromboembolic events in patients with patent foramen ovale and paradoxical embolism: long-term follow-up over more than 15 years. Clin Res Cardiol 2011; epub ahead of print.

31. Schuchlenz HW, Weihs W, Berghold A, et al. Secondary prevention after cryptogenic cerebrovascular events in patients with patent foramen ovale. Int J Cardiol 2005; 101: 77-82.

32. Kitsios GD, Dahabreh IJ, Abu Dabrh AM, et al. Patent foramen ovale closure and medical treatments for secondary stroke prevention: a systematic review of observational and randomized evidence. Stroke 2012; 43: 422-431.

33. NMT Medical Announces Preliminary Results of CLOSURE I PFO/Stroke Trial Company Release - 06/17/2010.

34. Kent DM, Thaler DE. Is patent foramen ovale a modifiable risk factor for stroke reccurence? Stroke 2010; 41 (Suppl 10): S26-S30.

35. Giacalone G, Abbas M, Corea F. Prevention strategies for cardioembolic stroke: present and future perspectives. Open Neurol J 2010; 4: 56-63.

36. Kent DM, Thaler DE. Risk of Paradoxical Embolism (RoPE) study: developing risk models for application to ongoing randomized trials of percutaneous patent foramen ovale closure for cryptogenic stroke. Trials 2011; 12: 185.

37. Doliwa Sobocinski $P$, Anggårdh Rooth E, Frykman Kull V, et al. Improved screening for silent atrial fibrillation after ischaemic stroke. Europace 2012 [Epub ahead of print] (Abstract).

38. Healey JS, Connolly SJ, Gold MR, et al.; ASSERT Investigators. Subclinical atrial fibrillation and the risk of stroke. N Engl J Med 2012; 366: 120-129.

39. St Jude Medical. St Jude Medical announces achievement of stopping rule nad closing of patients enrollment in RESPECT clinical trial (press release). January 3, 2012

40. Demkow M, Ruzyłło W, Kepka C, et al. Transcatheter closure of patent foramen ovale in patients with cryptogenic stroke. Kardiol Pol 2004; 61: 101-109.

41. Kumor M, Baranowski R, Jakubowska E, et al. Evaluation of cardiac arrythmias and conduction abnormalities one year after transcatheter closure of atrial septal defect and patent foramen ovale. Folia Cardiol 2002; 9: 553-558.

42. Khairy P, O’Donnell CP, Landzberg MJ. Transcatheter closure versus medical therapy of patent foramen ovale and presumed paradoxical thromboemboli: a systematic review. Ann Intern Med 2003; 139: 753-760.

43. Verma SK, Tobis JM. Explantation of patent foramen ovale closure devices: a multicenter survey. JACC Cardiovasc Interv 2011; 4: 579-585.

44. Sacco RL, Adams R, Albers G, et al. Guidelines for prevention of stroke in patients with ischemic stroke or transient ischemic attack: a statement for healthcare professionals from the American Heart Association/American Stroke Association Council on Stroke: co-sponsored by the Council on Cardiovascular Radiology and Intervention: the American Academy of Neurology affirms the value of this guideline. Stroke 2006; 37: 577-617. 
45. Furie KL, Kasner SE, Adams RJ, et al. Guidelines for the prevention of stroke in patients with stroke or transient ischemic attack a guideline for healthcare professionals from the American Heart Association/American Stroke Association. Stroke 2011; 42: 227-276.

46. Wilmshurst PT, Nightingale S, Walsh KP, Morrison WL. Effect on migraine of closure of cardiac right-to-left shunts to prevent recurrence of decompression illness or stroke or for haemodynamic reasons. Lancet 2000; 356: 1648-1651.

47. Peto R, Gray R, Collins R, et al. Randomized trial of prophylactic daily aspirin in British male doctors. Br Med J 1988; 296: 313-316.

48. Diener HC, Hartung E, Chrubasik J, et al. A comparative study of oral acetysalicyclic acid and metoprolol for prophylactic treatment of migraine. A randomized, controlled, double-blind, parallel group phase III study. Cephalagia 2001; 21: 120-128.

49. Jesurum JT, Fuller CJ, Kim CJ, et al. Frequency of migraine headache relief following patent foramen ovale "closure" despite residual right-to-left shunt. Am J Cardiol 2008; 102: 916-920.

50. Wilmshurst $P$, Nightingale $S$, Walsh $\mathrm{K}$, et al. Clopidogrel reduces migraine with aura after transcatheter closure of persistent foramen ovale and atrial septal defects. Heart 2005; 91: 1173-1175.

51. Azarbal B, Tobis J, Suh W, et al. Association of interatrial shunts and migraine headaches: impact of transcatheter closure. J Am Coll Cardiol 2005; 45: 489-492.

52. Wahl A, Praz F, Tai T, et al. Improvement of migraine headaches after percutaneous closure of patent foramen ovale for secondary prevention of paradoxical embolism. Heart 2010; 96: 967-973.

53. Lapergue B, Rosso C, Hadrane L, et al. Frequency of migraine attacks following stroke starts to decrease before PFO closure. Neurology 2006; 67: 1099-1100.

54. Dowson A, Mullen MJ, Peatfield R, et al. Migraine Intervention With STARFlex Technology (MIST) trial: a prospective, multicenter, double-blind, sham-controlled trial to evaluate the effectiveness of patent foramen ovale closure with STARFlex septal repair implant to resolve refractory migraine headache. Circulation 2008; 117: 1397-1404.

55. Torti SR, Billinger M, Schwerzmann M, et al. Risk of decompression illness among 230 divers in relation to the presence and size of patent foramen ovale. Eur Heart J 2004; 25: 1014-1020.

56. Vann RD, Butler FK, Mitchell SJ, Moon RE. Decompression illness. Lancet 2010; 377: 153-164.

57. Lynch J, Bove A. Diving medicine: a review of current evidence. J Am Board Fam Med 2009; 22: 399-407.

58. Kłopotowski M, Demkow M, Konka $M$, et. al. Percutaneous closure of patent foramen ovale after neurological decompression illness in divers. Post Kardiol Interw 2008; 411: 10-14. 